\title{
Criminologie
}

\section{Le citoyen face à la déviance}

\section{Laurent Laplante}

Volume 12, numéro 1, 1979

Justice et public

URI : https://id.erudit.org/iderudit/017101ar

DOI : https://doi.org/10.7202/017101ar

Aller au sommaire du numéro

Éditeur(s)

Les Presses de l'Université de Montréal

ISSN

0316-0041 (imprimé)

1492-1367 (numérique)

Découvrir la revue

Citer ce document

Laplante, L. (1979). Le citoyen face à la déviance. Criminologie, 12(1), 78-80.

https://doi.org/10.7202/017101ar d'utilisation que vous pouvez consulter en ligne.

https://apropos.erudit.org/fr/usagers/politique-dutilisation/ 
Quand le commerce s'empare des sandales, des colifichets et des pendantifs « hippies » et fait un bénéfice sur ces symboles de la contestation californienne, on a tôt fait de vanter « la force de récupération du système $»$. C'est là, en tout cas, une déviance désamorcée et absoute par sa rentabilité.

Quand les media consacrent 50 «séries》 de télévision aux réussites policières et aucune à la réhabilitation, ils se donnent vite bonne conscience : ils jettent ainsi, disent-ils, un oil vigilant et objectif sur la sordide et dangereuse réalité moderne. Il serait malséant et tout à fait stérile de rappeler à ces «machines à panique que les enquêtes policières piétinent et avortent dans $80 \%$ des cas ; tout aussi malséant et tout aussi stérile d'attirer leur attention sur le fait que la libération conditionnelle, dont ils ne disent mot dans leur survol serein et philanthropique, réussit, elle, quatre fois sur cinq. Pourquoi, dira-t-on, un tel aveuglement sélectif? Tout simplement parce que le spectacle de la déviance violente entretient d'admirable façon et avec une irremplaçable efficacité l'affolement et la docilité du public. Tout simplement parce que l'examen de la lente marche d'un individu vers sa réhabilitation justifie moins bien le gonflement des budgets policiers. Si l'on accordait donc à la déviance violente moins de temps d'antenne, la panique populaire refluerait et les empires policiers en seraient rognés d'autant. Comme quoi il existe une deuxième façon de rentabiliser la déviance.

Nous trouvons, plus haut encore dans la hiérarchie sociale, d'autres utilisations tout aussi efficaces de la déviance. Elles surviennent lorsque, par exemple, des chefs politiques flirtent avec la peine de mort et entretiennent savamment des préjugés populaires dont ils escomptent un bénéfice électoral. Dans de tels cas, la déviance amplifiée à plaisir, devient, en un sens de plus, éminemment rentable pour un certain pouvoir.

Rien ne sert de poursuivre sur ce terrain. En effet, de cet art qu'ont maints pouvoirs de tirer avantage de la déviance -

* Nous incluons ce texte sous la rubrique de témoignages puisque son auteur, éditorialiste très connu, a été également commissaire de la Commission Prévost sur \& L'administration de la justice criminelle et pénale au Québec » qui a présenté son rapport en 1969. 
réelle ou appréhendée - , on pourrait donner d'autres illustrations encore. Celles-ci devraient pourtant suffire à faire sentir l'ambivalence du public face à la déviance : comment une réalité aussi rentable pourrait-elle être aussi redoutable qu'on le dit?

Mais d'autres évidences surgissent à propos de la déviance. L'une des plus tenaces, c'est la présence, patente, énorme, scandaleuse, de la déviance pratiquée avec impudence dans les couches supérieures de la société.

Le drame, en ce sens, ce n'est pas Watergate ; c'est que Watergate n'étonne pas. Ce n'est pas la malhonnêteté de l'homme public ; c'est le terrible et massif verdict populaire selon lequel « ils sont tous pareils ». Le drame, ce n'est pas ce procès d'un maire de banlieue, ni ce maquignonnage des contrats olympiques, ni cet enrichissement à partir de cargaisons de viande avariée... Non. Le drame, c'est que le public attende, prédise, escompte la déviance de ses élites.

De fait, quand les horaires officiels des autobus interurbains garantissent aux voyageurs que la vitesse légale sera toujours et systématiquement dépassée, il y a déviance de la part de corporations et cécité coupable des surveillants. De fait, quand un gouvernement, au lieu de blâmer les policiers qui se sont permis en telle circonstance un comportement carrément criminel, modifie la loi de façon rétroactive et absout tardivement les gardiens de la loi de leur mépris de la loi, il y a déviance chez les policiers et collusion blâmable de la part des gouvernants. De fait, quand des syndicats tout-puissants traitent les lois comme je traite le journal de la veille, il y a déviance. De fait, quand d'énormes raffineries conspirent pour gonfler le prix du sucre et s'en tirent avec une amende pour elles presque symbolique, il y a déviance de la part de ces administrateurs instruits, déviance de la part du législateur qui se satisfait d'un texte plein de trous, déviance chez les magistrats qui ne soulignent pas le non-sens, déviance chez les media qui ne créent ni ne véhiculent de pressions populaires.

En somme, quand la déviance, non contente de profiter aux puissants qui savaient tantôt la harnacher, s'affiche maintenant comme une activité normale des cercles huppés, l'ambivalence du public s'amplifie et prend des visages plus belliqueux : pour- 
quoi, en effet, l'anathème qui pèse sur la déviance frappe-t-il de façon si sélective?

Gloser sur les instincts sanguinaires de la société, peut-être est-ce, par conséquent, passer au large du problème. Ergoter sur le présent virage à droite, peut-être est-ce même confondre la cause et l'effet. La réaction de la société face à la déviance, peut-être est-ce, en effet, dans son étonnante tolérance aussi bien que dans ses imprévisibles sursauts vengeurs, toujours et constamment la recherche d'une justice qui serait prévisible et universellement équitable? Si la tolérance vous étonne, c'est que vous avez oublié ce que le citoyen se rappelle : la force de récupération du système. $\mathrm{Si}$, au contraire, c'est le goût du sang qui vous bouleverse, c'est que vous avez oublié cet autre fait dont le citoyen se souvient : la scandaleuse et impudente déviance des nantis.

En somme, ce citoyen que l'on décrit comme un amateur de potence et de garrottage, n'est-il pas d'abord un être déçu des disparités et des incohérences? Et ce citoyen qui jette un clin d'œil à Lucien Rivard ou à Jacques Mesrine, n'est-il pas d'abord un être étonné de ce que tant de déviances soient rentables et de ce que tant de déviants roulent carosse ?

Une justice constamment fidèle à elle-même ne susciterait pas chez le citoyen la tentation de préférer la vengeance. Ni celle de fermer les yeux. 